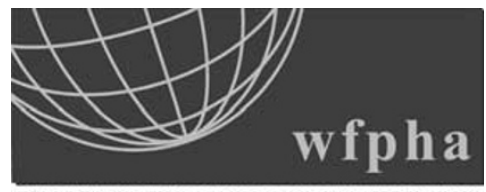

WORLD FEDERATION OF PUBLIC HEALTH ASSOCIATIONS

\title{
The Federation's Pages
}

\author{
WFPHA: World Federation of Public Health Associations \\ www.wfpha.org \\ Bettina Borisch, Federation's Pages Editor
}

Journal of Public Health Policy (2012) 33, 132-135. doi:10.1057/jphp.2011.54

\section{An invisible epidemic: Preventing unintentional injuries among children and youth - A priority for national Public Health Associations}

Injuries, a growing public health problem, are a leading cause of morbidity, disability, and death in children and youth globally. WHO and UNICEF found mortality among children and youth (10-24 years) amounts to 875000 or 40 per cent of recorded deaths due to injuries and violence. WHO's Global Status Report on Road Safety 2009 predicted road traffic injuries become the fifth leading cause of death by $2030,{ }^{1}$ and the seventh leading cause of disability-adjusted life years lost (p. 31). ${ }^{1}$ Burns, drowning, falls, and poisoning are other major causes. ${ }^{2}$ For every injured child who dies, several thousand survive with disabilities.

The road traffic death rate globally among children is 10.7 per 100000 . In sub-Saharan Africa it is almost twice that, 19.9 per 100000 . Increasing urbanization and car ownership, compounded by inadequate road and road safety infrastructure cause further increases (p. 31). ${ }^{2}$ Pedestrians constitute 68 per cent of all childhood road traffic injuries, with children walking to school at particularly high risk. Cyclists, motorcyclists, and informal public transport users are also at risk.

The content of The Federation's Pages is selected and edited by the WFPHA and not reviewed by JPHP. 
Regulatory laxity, increased risk-taking, reduced supervision of children, shared road space, and poor road construction all contribute to this picture. ${ }^{3}$ Research in Africa shows that poor children and youth (pedestrians, passengers in public transport, cyclists) are particularly vulnerable to road traffic injuries. Several family and household factors affect childhood injury risks, including, importantly, the mothers' safety training of children. ${ }^{3}$

Prevention of unintentional injury in children and youth (UICY) has received little attention, and thus constitutes an 'invisible element' of public health. While emergency rooms deal daily with the consequences of unintentional injuries, they are not a disease. Thus, this does not gain the same attention as do infectious and chronic diseases.

Progress is slow. In 2007, African leaders issued the Accra Declaration calling upon governments to improve injury and accident prevention through intersectoral action. ${ }^{4}$ In 2010, the UN General Assembly proclaimed 2011-2020 the Decade of Action for Road Safety. ${ }^{5}$ In January 2011, the WHO Executive Board resolved to include child injury prevention on the child survival agenda, to achieve Millennium Development Goal \#4 on child mortality. ${ }^{6}$ The 64th World Health Assembly in May 2011 passed a child injury prevention resolution. $^{7}$

Despite these actions born of best intentions, more tangible action is needed. Reliable estimates are lacking for the scale and patterns of injury and the context within which injuries occur (pp. 64, 167). ${ }^{1}$ We also lack knowledge about appropriate policies and best practices. Injury prevention advocates confront low public awareness of injury prevention and safety promotion, and, socio-economic inequalities create conditions that increase risks and limit capacity to respond. People believe that accidents are unpredictable, and thus by nature unavoidable, but this may not be true. Government responses are often under-resourced, and governments often lack means to implement existing policies and regulations.

National public health associations (PHA) are ideally suited to 'champion' this issue. PHAs work independently from government, are intersectoral, and can broker and support effective national responses. PHAs improve core public health competencies and national and local health systems capacities to respond. To improve national and community-led efforts to reduce risks associated with UICY, PHAs can advocate before government and NGOs for improved policy, programs, and practices.

The Canadian Public Health Association (CPHA), national PHAs in Ethiopia, Uganda, Tanzania, Mozambique, and Nicaragua, plus Safe Kids Canada prepared an initiative to improve the organizational and programmatic capacity of PHAs as civil society advocates and catalysts on UICY. ${ }^{8}$ We seek two expected intermediate outcomes: (a) improved evidence-based nationaland community-level responses to reduce injury in children and youth; and 
(b) stronger civil society capacity to catalyze better national-level practices, programs, and policies to prevent UICY, through increased

- understanding of what makes children and youth vulnerable to injuries;

- capacity to design and deliver community-based injury prevention activities;

- intersectoral collaboration in decision-making, and policy and program development;

- participation of PHAs in community, national, regional, and global efforts on injury prevention; and,

- awareness of PHA expertise in policy, programs, and practice to address injury prevention.

To define and address the needs of direct beneficiaries - children, youth, families, and communities - the project will adopt a participatory, communitybased approach, supporting civil society organizations and governments to mobilize and build community capacity. The goal is sound, evidence-informed policies and regulations, plus instruments that help design and deliver government- and community-sponsored programs. South-South technical cooperation will support national efforts to achieve MDGs, specifically MDG 4 (decrease in child mortality) and MDG 1 (decreased disability and loss of productivity that can help alleviate poverty). CPHA and Safe Kids Canada will provide technical advice and assistance to the five PHAs on this all-too-often 'invisible issue'.

Through the advocacy effects of the national PHAs and the World Federation of Public Health Associations, the global voice of the non-governmental public health community will contribute to prevent $\mathrm{UICY}$ and to improve the security and health of communities around the world.

James Chauvin, Director of Policy, Canadian Public Health Association (CPHA) and Vice President and President-Elect, World Federation of Public Health Associations (WFPHA) (E-mail: jchauvin@cpha.ca).

D.K. Sekimpi, Acting Executive Director, Uganda National Association for Community and Occupational Health (UNACOH).

Édio Paulino, Project Officer, Mozambique Public Health Association (AMOSAPU).

Bertha Maegga, Executive Secretary, Tanzania Public Health Association (TPHA).

I34 (C) 20 I 2 Macmillan Publishers Ltd. OI97-5897 Journal of Public Health Policy Vol. 33, I, I32-I35 
Hailegnaw Eshete, Executive Director, Ethiopian Public Health Association (EPHA).

Victor Méndez Dussán, President, Nicaraguan Public Health Association (ANSAP).

\section{Pamela Fuselli, Executive Director, Safe Kids Canada.}

\section{References and Notes}

1. World Health Organization. (2009) Global Status Report on Road Safety: Time for Action, p. ix.

2. World Health Organization, United Nations Children's Fund. (2008) World Report on Child Injury Prevention, p. 37.

3. Ruiz-Casares, M. (2009) Unintentional childhood injuries in sub-Saharan Africa: An overview of risk and protective factors. Journal of Health Care for the Poor \& Underserved 20(4): 51-67.

4. Economic Commission for Africa and the World Health Organization. (2007) Accra declaration: Declaration for African Ministers responsible for transport and health, http://www.who.int/ roadsafety/events/4arsc/accra_declaration.pdf, accessed 4 April 2011.

5. WHO. United Nations road safety collaboration, http://www.who.int/roadsafety/decade_of_ action/en/index.html, and Decade of Action for Road Safety 2011-2020, http://www.who.int/ violence_injury_prevention/en/index.html, accessed 1 June 2011.

6. WHO. (2011) WHO's Executive Board adopts resolution on child injury prevention. 27 January, http://www.who.int/violence_injury_prevention/media/news/2011/27_01/en/index.html.

7. WHO. (2011) Child injury prevention. Sixty-fourth World Health Assembly WHA 64.27. 24 May, http://apps.who.int/gb/ebwha/pdf_files/WHA64/A64_R27-en.pdf, accessed 9 June 2011.

8. The initiative's proposal was submitted to the Canadian International Development Agency for funding consideration in April 2011. At the time of this article's preparation, a decision by CIDA is pending. 